\title{
Within-day variation and effect of acute stress on plasma and milk cortisol in lactating goats
}

\author{
G. Romero, ${ }^{1}$ I. Restrepo, R. Muelas, J. Bueso-Ródenas, A. Roca, and J. R. Díaz \\ Departamento de Tecnología Agroalimentaria, Escuela Politécnica Superior de Orihuela, Universidad Miguel Hernández, 03312 Orihuela, Spain
}

\begin{abstract}
An experiment was carried out to study the effect of acute stress on cortisol concentration in goat milk (milk cortisol; MC) and its suitability for stress assessment. Additional variables studied were plasma cortisol (PC), blood glucose (BG), and somatic cell count (SCC). Ten goats free of mastitis at 2 mo of lactation were divided into 2 groups. One group of animals was exposed to acute stress (visual and auditory, but not physical, contact with a barking dog for $3 \mathrm{~min}$ ) immediately before the $1000 \mathrm{~h}$ sampling (STR), and the other group was considered as the control group, not exposed to acute stress $(\mathrm{CON})$. The animals were gradually accustomed to the sampling schedule for 1 wk before the stress treatment (pre-experimental period). The variables PC, MC, BG, SCC, and milk composition (fat, lactose, whey protein, true protein, and casein) were recorded at $0600,1000,1130,1400,1800,2200$, and $0200 \mathrm{~h}$. Milk variables were recorded in both glands separately. The right gland $(\mathrm{n}=10)$ was completely milked and the left gland ( $\mathrm{n}=10)$ was milked to $30 \mathrm{~mL}$ at every sampling except at $1000 \mathrm{~h}$, when complete milking was carried out on both glands. Variables were analyzed by using a linear mixed model. Both $\mathrm{PC}$ and $\mathrm{MC}$ concentrations varied throughout the day, with values being highest in the morning. Higher PC levels were recorded in the STR group immediately after treatment compared with CON (36.9 vs $16.3 \mathrm{ng} / \mathrm{mL}$ ). For MC, differences between treatments were noted $1.5 \mathrm{~h}$ after STR treatment (1.27 vs $0.25 \mathrm{ng} / \mathrm{mL}$ ). Blood glucose increased immediately after treatment in STR animals, being different from CON until $1.5 \mathrm{~h}$ after treatment sampling (101 vs. $58 \mathrm{mg} / \mathrm{dL}$ ). The SCC was not increased by STR treatment, showing higher values in the morning and afternoon compared with evening and night $(5.6 \pm 0.13$ to $5.87 \pm 0.13 \log _{10}$ SCC). The STR treatment had no significant effect on milk composition, and overall milk yield of a complete day after stress stimulus of both groups was similar (STR: 2,067 $\pm 280 \mathrm{~g} / \mathrm{d}$; CON: 2,134
\end{abstract}

Received February 14, 2014.

Accepted October 28, 2014.

${ }^{1}$ Corresponding author: gemaromero@umh.es $\pm 427 \mathrm{~g} / \mathrm{d})$. We conclude that plasma and milk cortisol concentrations in control dairy goats varied throughout the day; MC showed significant differences in the STR group if samples were taken $1.5 \mathrm{~h}$ after the stressing stimulus, whereas PC showed significant differences in samples taken immediately after the stressing stimulus. Additionally, MC sampling has the advantage of being noninvasive compared with blood sampling.

Key words: cortisol, blood glucose, somatic cell count, goat stress

\section{INTRODUCTION}

Animals react to stress with physiological and behavioral responses (Van Reenen et al., 2002), which are the results of individual emotional reactivity; however, behavioral measurements involve a very long and difficult process. The physiological response to stress includes activation of the central nervous, endocrine, and immune systems. The three systems are connected through the triggering of the autonomic nervous system and the hypothalamic-pituitary-adrenal (HPA) axis by the secretion of neuropeptides and neurohormones, which are responsible for changes in cellular and humoral immune responses.

Plasma cortisol (PC) is considered a reliable physiological endpoint for determining animal response to stress. Several studies (the first was published by Smith et al., 1972) have examined changes in PC or glucocorticoid concentrations in animals under different stressful conditions. A study by Hopster et al. (2002) showed that assessment of animal well-being requires procedures that can be stressful for animals. Several studies have been conducted to determine welfare indicators in biological fluids other than blood, such as milk cortisol (MC; Verkerk et al., 1998), salivary cortisol (Greenwood and Shutt, 1992; Negrão et al., 2004), urine cortisol (Higashiyama et al., 2007), or fecal cortisol (Palme and Mostl, 1997). Determination of welfare indicators in milk has the advantage of using noninvasive sampling, which might be useful when evaluating stress in milking ruminants because the sampling itself does not induce stress. Díaz et al. (2013) studied MC during lactation of Murciano-Granadina goats and concluded 
that this variable is suitable to assess the extent to which extrinsic factors (e.g., management, mechanical milking, food, type of housing, environmental conditions) cause stress, affecting the animals' well-being. To our knowledge, no studies have monitored the maximum concentration of MC after an acute stress situation, and understanding its degradation time would help to establish the best time for sampling after a stress situation for stress determination.

The aim of the work was to study the effect of acute stress on cortisol concentration in milk and its service life [the period (time) the hormone can indicate stress and be useful for that aim] for stress determination. Additionally, we assessed the effect of acute stress on PC and blood glucose (BG) concentrations.

\section{MATERIALS AND METHODS}

\section{Animal Management and Housing}

The experiment was carried out at the Experimental Farm of Escuela Politécnica Superior de Orihuela (Universidad Miguel Hernández de Elche, Spain). The installation has a main house with an exercise yard that the animals can access during the day. The milking parlor was low-line Casse type with self-locking gates, $1 \times 12 \times 12$ (number of platforms $\times$ number of stalls/ platform $\times$ number of milking units/platform), and automatic cluster removers (GEA Farm Technologies, Bönen, Germany).

The production system was intensive, with permanent stabling, 1 parturition per year, and machine milking once a day (at $1000 \mathrm{~h}$ ) from parturition. Milking parameters were 90 pulses/min of pulsation rate, 40 $\mathrm{kPa}$ of vacuum level, and $60 \%$ of pulsation ratio. Goats were offered $1.5 \mathrm{~kg}$ of a commercial concentrate (G-62, Alimer S. Coop, Lorca, Spain), $0.5 \mathrm{~kg}$ of oats, and 0.4 $\mathrm{kg}$ of alfalfa hay per goat and day divided in 2 portions.

\section{Experimental Design and Studied Variables}

Ten primiparous Murciano-Granadina goats at 2 mo of lactation ( $63 \pm 8 \mathrm{DIM})$, free of mastitis, normal body condition (3 to 3.5 ), and with milk yield between 1.5 and $2.5 \mathrm{~kg} / \mathrm{d}$ were selected from a group of 49 goats from a pre-experimental test carried out $15 \mathrm{~d}$ before the experiment. Mammary gland health status was determined by means of 3 bacteriological and SCC analyses, each $7 \mathrm{~d}$ apart, before the experiment. Goats were considered mastitis-free if results of bacteriology of both glands were negative (according to National Mastitis Council methodology, Harmon et al., 1990), and SCC were $<1,000,000$ cells $/ \mathrm{mL}$, as described by Díaz et al. (2011). The 10 goats selected were split into 2 groups of 5 goats with similar daily milk yields and SCC. One group was used for acute stress treatment (STR: 1,952 $\pm 317 \mathrm{~g} / \mathrm{d}$ of yield, and $\left.379 \pm 336 \times 10^{3} \mathrm{SCC} / \mathrm{mL}\right)$ and the other was used as control $(\mathbf{C O N}$ : 2,007 $\pm 391 \mathrm{~g} / \mathrm{d}$, and $\left.274 \pm 327 \times 10^{3} \mathrm{SCC} / \mathrm{mL}\right)$. Selected goats were managed under the same conditions during the week before the acute stress treatment to adapt them to experimental conditions. During this period, samplings were performed with the same frequency and methodology as in the experimental period but not analyzed. The experimental period lasted for $28 \mathrm{~h}$. Animals were sampled at $0600,1000,1130,1400,1800$, and $2200 \mathrm{~h}$ of one day, and 0200,0600 , and $1000 \mathrm{~h}$ of the following day, in the milking parlor. Animals were led to the milking parlor without stress, and a jugular blood sample $(5 \mathrm{~mL})$ was taken and preserved with EDTA (BD Vacutainer, Becton, Dickinson and Company, Franklin Lakes, NJ). Then, a milk sample was taken from every mammary gland by manual milking: $30 \mathrm{~mL}$ from left gland $(\mathrm{n}=10)$ and the total amount of right gland $(\mathrm{n}=10)$, except for the $1000 \mathrm{~h}$ sampling, when both glands were completely machine milked (milk samples were taken using volumetric measurement devices). The left-gland data were representative of the evolution of the concentration of variables when milking is carried out once a day (as in the majority of commercial farms of this goat breed), whereas the right-gland data indicate the evolution of the concentration of variables at every studied time. To study the effect of stress on the recorded variables in the experimental period before the $1000 \mathrm{~h}$ sampling, only STR animals were exposed to acute stress. The stressing stimulus consisted of taking goats to an isolated and unfamiliar barnyard $(20 \mathrm{~m}$ distant) and exposing them to visual and auditory (but not physical) contact with a barking dog for 3 min, after which goats were taken to the milking parlor for sampling, with the entire process taking $10 \mathrm{~min}$. At the end of the experimental period, mammary gland health status was confirmed by means of the same methodology used for animal selection (described above).

\section{Analyzed Variables}

Concentrations of PC $(\mathrm{ng} / \mathrm{mL})$ and $\mathrm{MC}(\mathrm{ng} / \mathrm{mL})$ were analyzed from plasma and skim milk samples, respectively, obtained after centrifugation at 2,000 $\times$ $g$ at $5^{\circ} \mathrm{C}$ for $20 \mathrm{~min}$ (K-40, Centurion Scientific Ltd., Chichester, UK). Cortisol analyses were performed at the Endocrinology Laboratory of Veterinary Faculty of Universidad Complutense de Madrid (Spain) using an ELISA method developed to quantify cortisol in bovine saliva (Chacón et al., 2004) and validated for goats following methods described by Munro and Lasley (1988). Extraction of cortisol from skim milk samples 
was performed using a method similar to that described by Hagen et al. (2004) for bovine skim milk. Cortisol was extracted from $100 \mu \mathrm{L}$ of skim milk samples and plasma using $2 \mathrm{~mL}$ of diethyl ether.

Blood glucose $(\mathrm{mg} / \mathrm{dL})$ was analyzed directly on blood using a portable glucometer (Mediasense Optium Exceed, Abbott Laboratories, Abbott Park, IL). Strips had been previously calibrated by the manufacturer. Somatic cell count and milk composition were analyzed in the Animal Production Laboratory of the Departamento Tecnología Agroalimentaria, Universidad Miguel Hernandez (Orihuela, Spain). Somatic cell count (SCC $\times 10^{3}$ cells $/ \mathrm{mL}$ ) was analyzed using a portable DeLaval Cell Counter and one-use disposable cartridges (DeLaval, Tumba, Sweden). Milk composition (measured in $\mathrm{g} / 100 \mathrm{~g}$ of milk, fat, lactose, whey protein, true protein, and casein) was analyzed using a medium infrared spectrophotometer (MilkoScan FT 120, Foss, Hillerød, Denmark) which was calibrated for goat milk. Only milk from the right gland was analyzed.

\section{Statistical Analysis}

The distribution of variables was analyzed through histograms and normality test (Proc Univariate of SAS, version 9.2; SAS Institute Inc., Cary, NC). The SCC was $\log$ transformed to normalize its distribution. The relationship between the dependent variables and the fixed and random effects was analyzed using a linear mixed model (Proc Mixed of SAS). To study PC, BG, and milk composition (fat, lactose, whey protein, true protein, and casein), the fixed effects considered were treatment (2 levels: STR and CON), sampling time (9 levels: 0600, 1000, 1130, 1400, 1800, 2200, 0200, 0600, and $1000 \mathrm{~h}$ ), and the interaction between treatment and sampling time. The animal was considered as random effect and a compound-symmetry covariance structure was used to consider repeated measures over time in the same animal. The model using this hierarchical structure provided the best fit for the data compared with different models considering other covariance and hierarchical structures (as assessed using Bayesian and Akaike information criteria). To study MC and SCC, in addition to the previously mentioned fixed effects, the mammary gland (gland, 2 levels: left and right), and interactions between sampling time and gland and between treatment and gland were considered. Moreover, gland nested in goat was considered as random effect and a compound-symmetry covariance structure was used to consider repeated measures over time in the mammary glands (assessed using Bayesian and Akaike information criteria). To study the relationship of PC with MC and BG, regression (Proc Reg of SAS) and correlation (Proc Corr of SAS) analyses were done. Ad- ditionally, we studied the relationship of SCC and MC with regression and correlation analyses using the same procedures of SAS.

\section{RESULTS AND DISCUSSION}

For $\mathrm{PC}$ and $\mathrm{BG}$, significant effects were sampling time $(F=10.56, P<0.0001 ; F=16.52, P<0.0001$, respectively) and the interactions between treatment and sampling time $(F=2.38, P=0.026 ; F=21.61$, $P<0.001$, respectively), but treatment effects on the general means were not significant $(F=4.61, P=$ $0.064 ; F=0.06 ; P=0.817)$. The significant interactions between treatment and sampling time indicate that the variables had different results between treatments among sampling times (Figures 1 and 2).

The values of $\mathrm{PC}$ in $\mathrm{CON}$ ranged throughout the day from 2.11 to $18.41 \mathrm{ng} / \mathrm{mL}$, consistent with results from goats without stress factors and similar to results published by Toerien et al. (1999). The PC concentration in CON increased at the $0600 \mathrm{~h}$ sampling (sunrise, early morning), and the highest values were obtained at $1000 \mathrm{~h}$ on both days (milking time); then, values decreased to reach basal levels at $1130 \mathrm{~h}$; PC was significantly higher at $1000 \mathrm{~h}$ than at any time between $1130 \mathrm{~h}$ and $0200 \mathrm{~h}$ (Figure 1). Wagner and Oxenreider (1972), Lefcourt et al. (1993), and Verkerk et al. (1998) found similar results in dairy cows: maximum levels of PC were found in the early morning, decreasing thereafter to reach their lowest levels during the afternoon and evening period. Those authors suggest that this variation could be related to daylight or to the onset of the animals' daily activity. However, Alila-Johansson et al. (2003), in a study with Criollo goats using different lighting levels and constant temperature, suggested that circadian variation of cortisol secretion is completely determined by external factors, and lighting conditions do not have immediate effects on daily secretion patterns.

Levels of PC in STR throughout the day varied similarly to CON until stress was initiated. The only significant differences between groups were found in the milking immediately following acute stress (1000 h) and at $1130 \mathrm{~h}$. At $1000 \mathrm{~h}$, the concentration of PC in STR was twice that of CON $(37 \pm 3.6$ vs. $16.9 \pm$ $3.6 \mathrm{ng} / \mathrm{mL}$, respectively), a significant difference $(P<$ $0.001)$. At $1130 \mathrm{~h}(1.5 \mathrm{~h}$ after stress treatment), PC decreased in both treatments $(13.4 \pm 3.6 \mathrm{ng} / \mathrm{mL}$ vs. $2.6 \pm 3.6 \mathrm{ng} / \mathrm{mL}$ for STR and CON, respectively; $P=$ 0.041). In the subsequent sampling, at $1400 \mathrm{~h}$ (240 min after stressful treatment), both treatments had lower and similar PC levels. These results agreed with those of Båge et al. (2000), who observed that, after an injection of ACTH, the maximum cortisol level (registered 


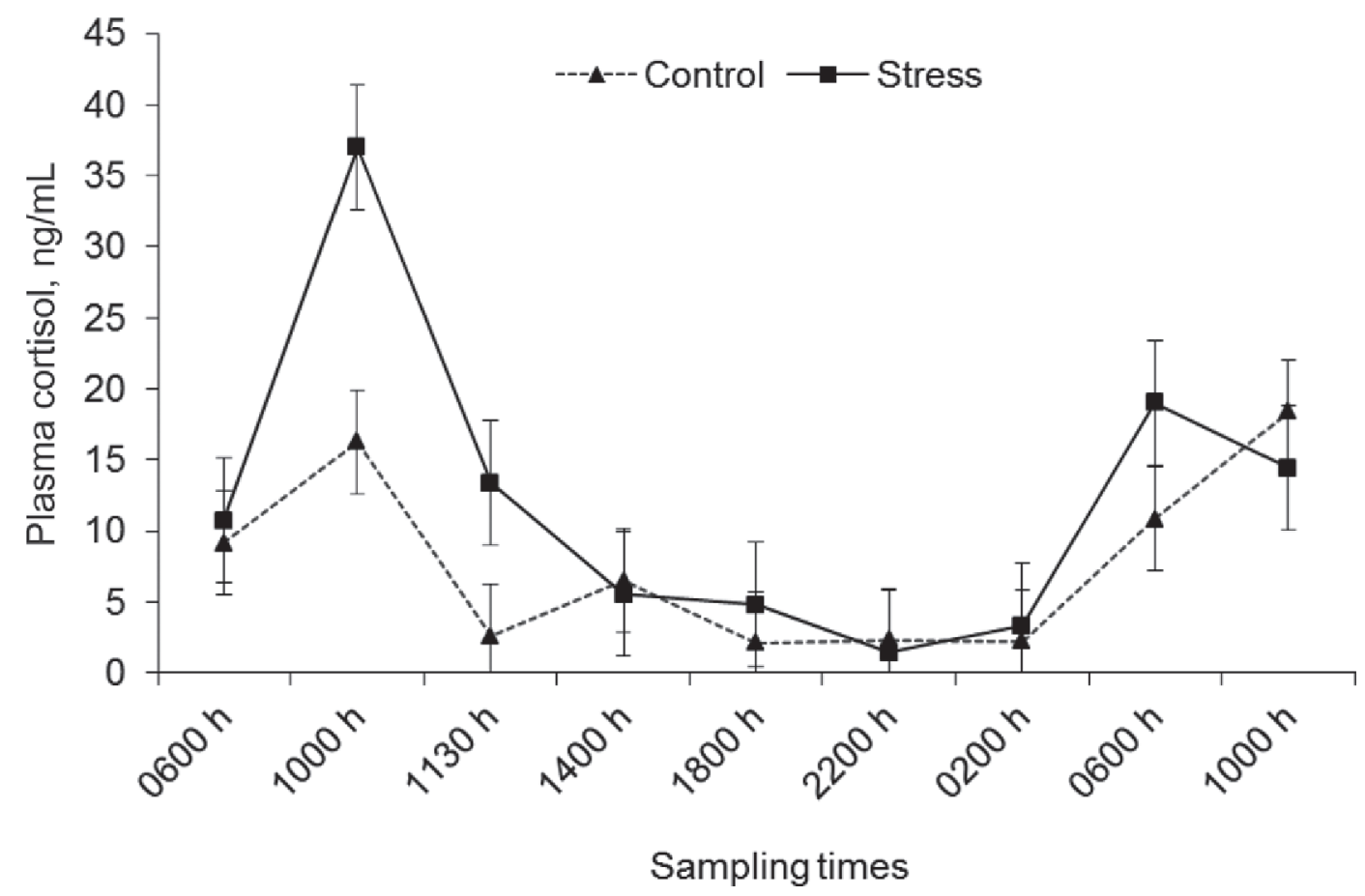

Figure 1. Effect of sampling time and treatment on plasma cortisol concentration. Milkings were done at $1000 \mathrm{~h}$ on consecutive days. Animals in the stress treatment were exposed to acute stress (visual and auditory, but not physical, contact with a barking dog for 3 min) immediately before $1000 \mathrm{~h}$; the control animals were not exposed to acute stress. Error bars indicate SEM.

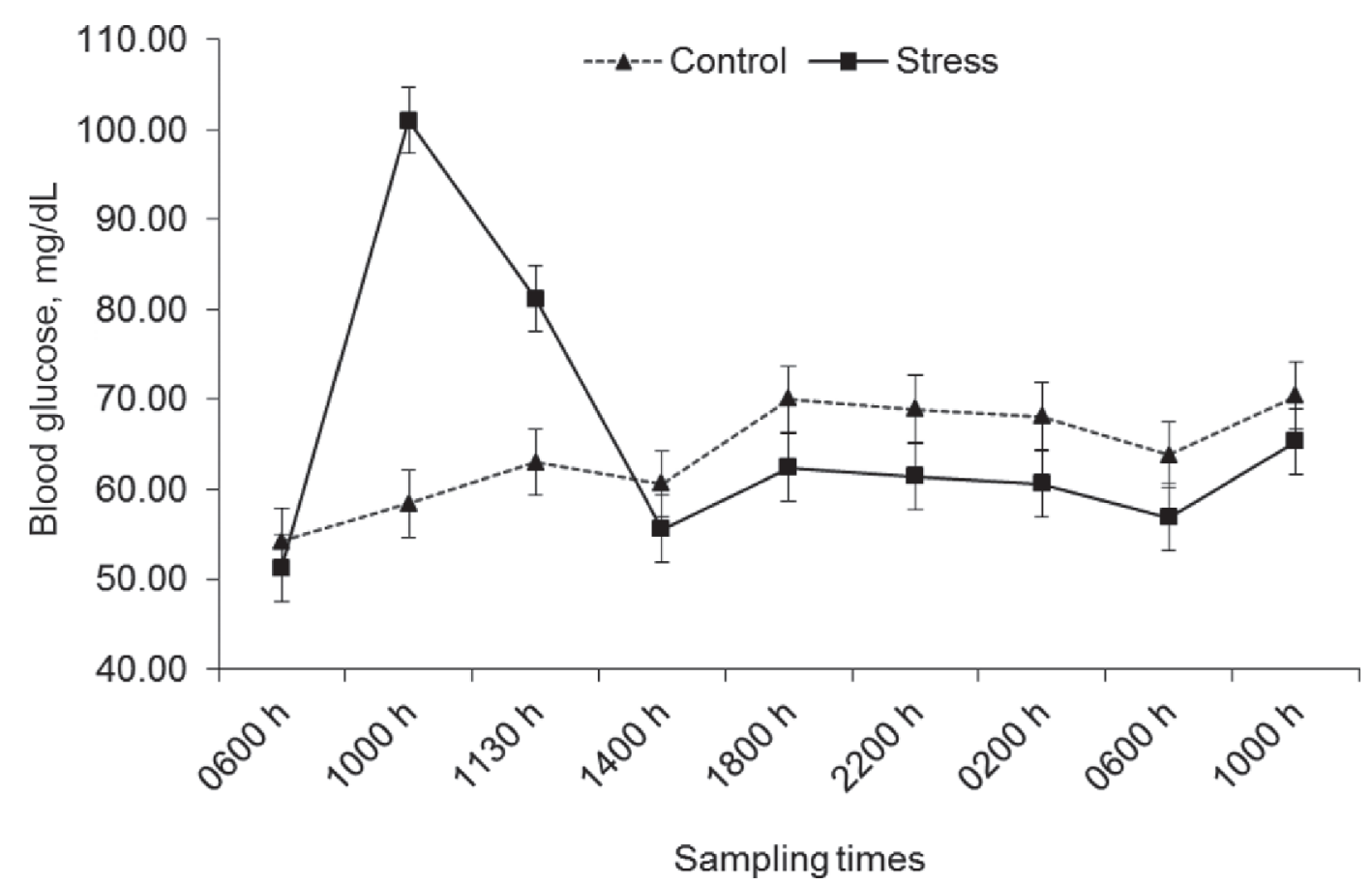

Figure 2. Effect of sampling time and treatment on blood glucose concentration. Milkings were done at $1000 \mathrm{~h}$ on consecutive days. Animals in the stress treatment were exposed to acute stress (visual and auditory, but not physical, contact with a barking dog for 3 min) immediately before $1000 \mathrm{~h}$; the control animals were not exposed to acute stress. Error bars indicate SEM. 
60 min after injection) returned to basal levels after 270 min, although the maximum levels observed in the current study were recorded immediately after the stress treatment. The concentration of PC increased at 0600 and $1000 \mathrm{~h}$ similarly in CON and STR goats, with no differences between treatments $(14.4 \pm 3.6$ vs. $18.4 \pm$ $3.6 \mathrm{ng} / \mathrm{mL}$, respectively).

Mean BG concentrations in CON (54 mg/dL) were slightly higher than those reported by Cabiddu et al. (1999) in goats at 2 mo of lactation. Blood glucose showed a significant increase in STR compared with CON in samples taken at $1000 \mathrm{~h}(+74 \% ; 101.0 \pm 3.86$ vs. $58.4 \pm 3.86 \mathrm{mg} / \mathrm{dL}$, respectively) and at $1130 \mathrm{~h}$ $(+28 \% ; 81.2 \pm 3.86$ vs. $63.0 \pm 3.86 \mathrm{mg} / \mathrm{dL}$, respectively), returning to previously recorded values in the next sampling and not showing any significant difference between treatments in the remainder of the samplings (Figure 2). These results agree with those published by Ndibualonji et al. (1995), who observed a significant increase of glucose in plasma after a single low dose of ACTH in lactating cows, and by Mudron et al. (2005), who observed an increase of blood glucose after surgery. The increase in the availability of glucose in blood after a few minutes of stressing stimulus can be explained by the effects of glucocorticoids on metabolism, inhibiting the secretion of insulin and stimulating the secretion of glucagon, as observed by Ndibualonji et al. (1995) in cows. For BG, no relevant increases were recorded related to milking time (as seen for PC) but a large increase was recorded for the STR treatment.

The variables SCC and MC were affected by sampling time $(F=8.30, P<0.001 ; F=15.30, P<0.001$, respectively); $\mathrm{MC}$ was also affected by the interaction between sampling time and treatment $(F=2.36, P=$ 0.021 ), showing differences between treatments (CON and STR) at $1130 \mathrm{~h}$ (the sampling after the stressful treatment). Somatic cell count was affected by gland and by the interaction between sampling and gland ( $F$ $=6.49, P=0.012 ; F=2.13, P=0.036$, respectively). Treatment and the interaction between treatment and gland had no effect on any variable $(P>0.05)$. The highest MC values were recorded at $1000 \mathrm{~h}$, but differences between treatments were significant at 1130 $\mathrm{h}$ (Figure 3), returning to basal levels in STR at 1400 $\mathrm{h}$. This indicates that cortisol increases more slowly in milk than in plasma, and milk sampling to detect differences due to a stressful stimulus should be done $1.5 \mathrm{~h}$ after the stress stimulus. Samplings at $0600 \mathrm{~h}$ and $1000 \mathrm{~h}$ on the following day registered slightly higher values than previous samplings, without significant differences, and were significantly lower than values at $1000 \mathrm{~h}$ on the previous day (stress time). The lack of significant effect of the interaction between treatment and gland shows that cortisol did not accumulate in the mammary gland that was not completely milked (which stored milk excreted immediately after acute stress). This indicates that cortisol was metabolized and disappeared from the animal and from the udder, as observed by Fox et al. (1981). The advantage of MC compared with $\mathrm{PC}$ is that sampling of $\mathrm{MC}$ is easier and not stressful for the animal, which makes it useful for experimental determinations.

Somatic cell count showed a significant increase in samples taken at $1130 \mathrm{~h}$ compared with $0600 \mathrm{~h}$ in both treatments, especially in STR, but no significant differences between treatments were observed (Figure 4). This lack of difference between treatments is in contrast to results published by Caroprese et al. (2010), who observed, in an experiment in dairy ewes where animals were divided into high-cortisol and low-cortisol ewes, that SCC was higher in milk from high-cortisol ewes than in that from low-cortisol ewes. Mehdid (2009) observed that, in goats exposed to an extreme and acute stress stimulus (e.g., exposure to a dog), blood cortisol levels increased but SCC was only significantly increased in the oldest animals. In cattle, Whittlestone et al. (1970) demonstrated that isolation of the animals or exposure to a dog increased SCC but that the increase was greater in animals that had a previous history of mastitis. The differences between those studies and the current study could be explained by the fact that the animals used in this study were all primiparous and free of mammary gland infections. In comparing SCC between glands, the highest differences were recorded at $1000 \mathrm{~h}$ (right glands did not have significantly higher SCC than left glands: $5.74 \pm$ 0.18 vs. $5.45 \pm 0.18 \log _{10}$ SCC, respectively). This is because, at $1000 \mathrm{~h}$, the right glands had been completely milked in previous samplings, whereas the left glands retained milk secreted previously, so the somatic cells entering the gland were diluted, resulting in a lower SCC in the left glands. The complete emptying of the left gland at $1000 \mathrm{~h}$ caused a significant increase in SCC at $1130 \mathrm{~h}$, reaching values similar to that of the right gland (5.85 vs $5.84 \log _{10}$ SCC, respectively). Results obtained in CON show SCC secretion differences throughout the day; SCC increased significantly in the mid-morning hours, being lowest in evening and night hours, in primiparous goats in the absence of mastitis. This within-day variation agrees with other published studies in dairy cattle (Smith and Schultze, 1967) and sheep (Gonzalo et al., 1994).

Overall milk yield $( \pm \mathrm{SD})$ of a complete day after stress stimulus (from 1130 to $1000 \mathrm{~h}$ of the following day) was 2,067 $\pm 280 \mathrm{~g} / \mathrm{d}$ in STR and 2,134 $\pm 427 \mathrm{~g} / \mathrm{d}$ in CON, similar to reported yields in the preexperimental period (STR: 1,952 $\pm 317 \mathrm{~g} / \mathrm{d}$, CON: 2,007 \pm 391 $\mathrm{g} / \mathrm{d})$. For milk composition variables, only sampling 


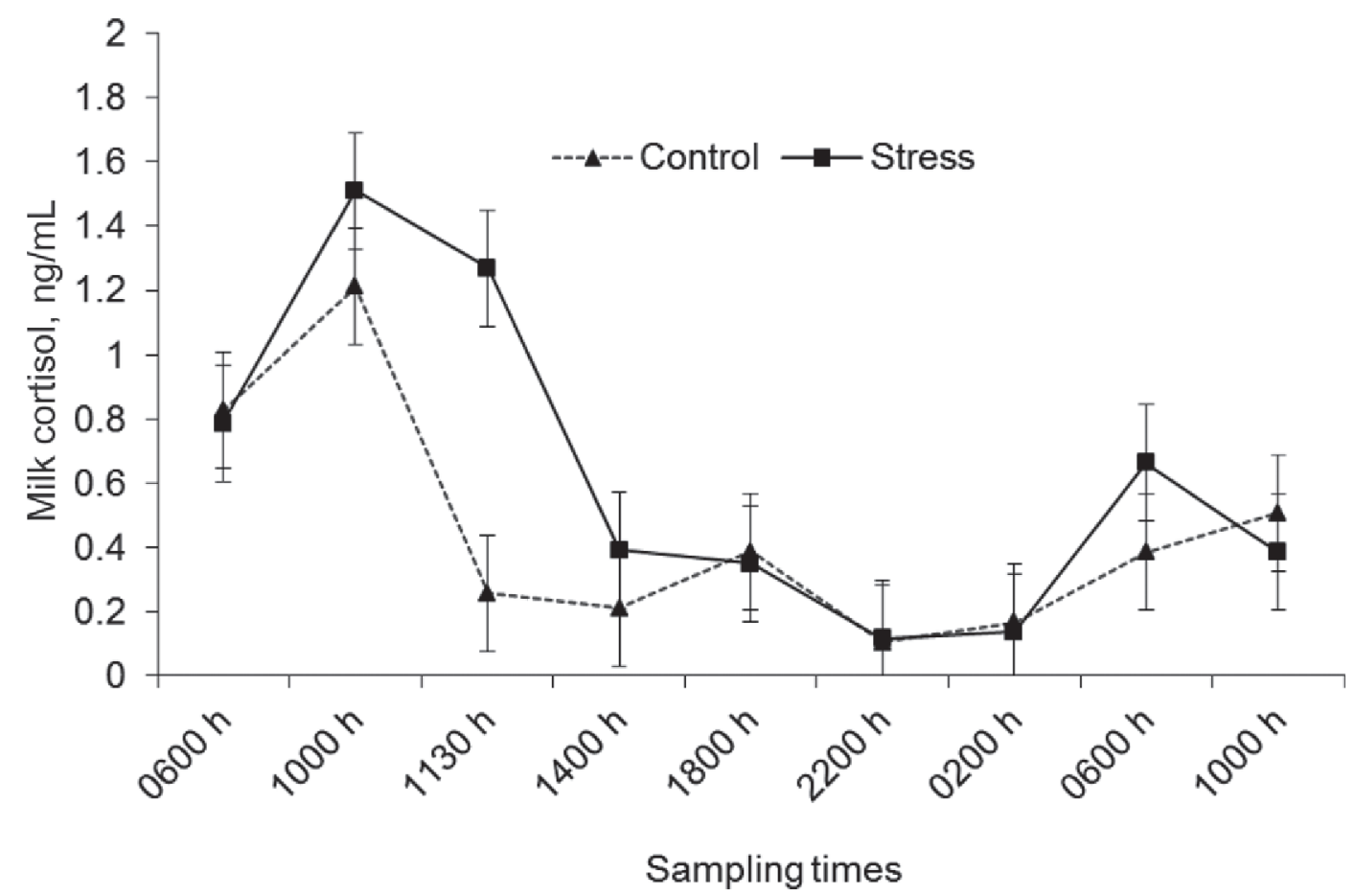

Figure 3. Effect of sampling time and treatment on milk cortisol concentration. Milkings were done at $1000 \mathrm{~h}$ on consecutive days. Animals in the stress treatment were exposed to acute stress (visual and auditory, but not physical, contact with a barking dog for 3 min) immediately before $1000 \mathrm{~h}$; the control animals were not exposed to acute stress. Error bars indicate SEM.

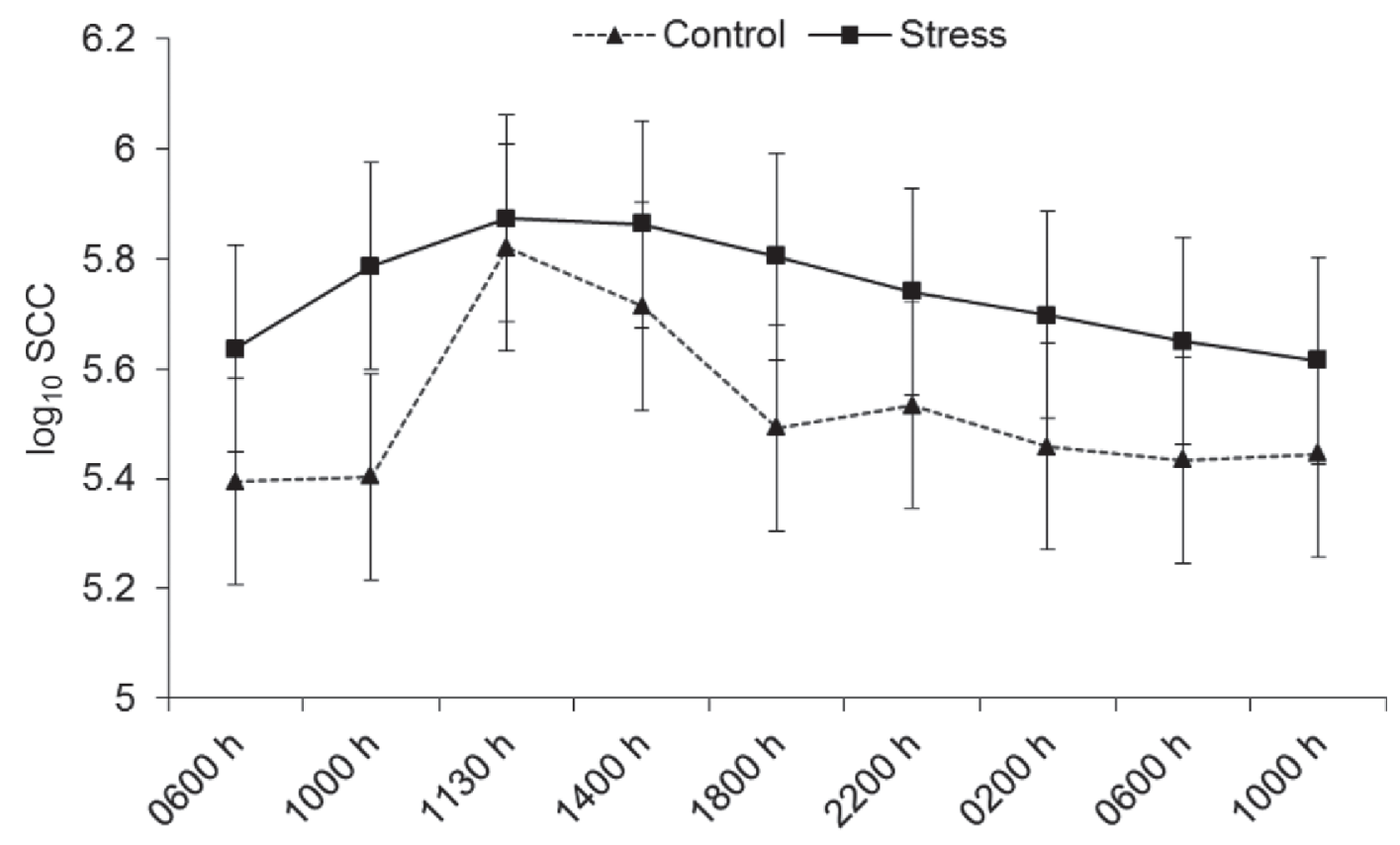

Sampling times

Figure 4. Effect of sampling time and treatment on SCC. Milkings were done at $1000 \mathrm{~h}$ on consecutive days. Animals in the stress treatment were exposed to acute stress (visual and auditory, but not physical, contact with a barking dog for 3 min) immediately before $1000 \mathrm{~h}$; the control animals were not exposed to acute stress. Error bars indicate SEM. 
time was significant $(P<0.001)$. Treatment and the interaction of sampling with treatment were not significant. Means $( \pm \mathrm{SE})$ of CON and STR showed small and nonsignificant differences (lactose: $4.01 \pm 0.07$ vs. $4.05 \pm 0.07$; fat: $5.14 \pm 0.012$ vs. $5.02 \pm 0.12$; caseins: $2.86 \pm 0.06$ vs. $2.96 \pm 0.06$; serum protein: $0.51 \pm 0.03$ vs. $0.52 \pm 0.03 \%$ humid matter, respectively). The lack of effect of the interaction of sampling and treatment on these variables showed that short-term acute stress had no effect on the secretion of milk components, in agreement with the study by Caroprese et al. (2010). These results, especially those obtained in the CON treatment, indicate the circadian rhythm of secretion. The analysis of fat showed the highest values at 1000 $\mathrm{h}$ in STR and at $1130 \mathrm{~h}$ in CON (without significant differences between treatments at both times). No published studies on the daily evolution of these variables in goats were found, but a study by Gilbert et al. (1973) in Holstein cows milked at 12-h intervals showed higher milk fat and protein at the evening milking, in contrast to our results.

A significant $(P<0.01)$ positive correlation $(\mathrm{r}=$ 0.51) was observed between PC and BG concentrations, in accordance with the cited effect on metabolism of glucocorticoids, which stimulate the secretion of glucagon and hence glucose. The correlation of PC with MC was similar to that obtained by Fox et al. $(1981 ; r=0.55)$ but lower than obtained by Termeulen et al. $(1981 ; \mathrm{r}=0.91)$. Both of the earlier studies were carried out in cows and both concluded that $\mathrm{MC}$ is a simple method to monitor PC. Nevertheless, regression analyses showed a small and significant determination coefficient $\left(\mathrm{PC}=6.42+5.92 \mathrm{MC} ; \mathrm{R}^{2}=0.23, P<\right.$ 0.001). Similarly, a positive and significant correlation was observed between PC and BG $(\mathrm{r}=0.52 ; P<0.01)$, but a small determination coefficient was obtained (PC $\left.=-14.25+0.37 \mathrm{BG} ; \mathrm{R}^{2}=0.19 ; P<0.001\right)$. Milk cortisol showed a similar pattern as PC (Figures 1 and 3), similar to results obtained by Fox et al. (1981), Termeulen et al. (1981), and Verkerk et al. (1998), who affirmed that milk cortisol concentration is related to blood cortisol concentration during milk synthesis (as observed in this study), it being more likely that cortisol returns to the blood from the alveoli than from the udder cistern (Verkerk et al., 1998).

The variables $\mathrm{PC}$ and $\mathrm{MC}$ increased in the stressed animals but SCC did not increase, so there was no correlation between SCC and $\mathrm{PC}$ or MC.

\section{CONCLUSIONS}

Cortisol concentrations in nonstressed dairy goats varied throughout the day; milk cortisol showed significant differences in stressed goats in samples taken 1.5 $\mathrm{h}$ after the stressing stimulus, whereas plasma cortisol showed significant differences in samples taken immediately after the stressing stimulus. The similar pattern of PC and MC obtained throughout the day and after stressing stimulus indicates that milk cortisol analysis is a valid and noninvasive method for detecting acute stress in lactating goats.

\section{ACKNOWLEDGMENTS}

The study was supported by project AGL2009-10695 (Ministerio de Ciencia e Innovación, Madrid, Spain).

\section{REFERENCES}

Alila-Johansson, A., L. Eriksson, T. Soveri, and M. Laakso. 2003. Serum cortisol levels in goats exhibit seasonal but not daily rhythmicity. Chronobiol. Int. 20:65-79.

Båge, R., M. Forsberg, H. Gustafsson, B. Larsson, and H. RodríguezMartínez. 2000. Effect of ACTH-challenge on progesterone and cortisol levels in ovariectomised repeat breeder heifers. Anim. Reprod. Sci. 63:65-75.

Cabiddu, A., A. Branca, M. Decandia, A. Pes, P. M. Santucci, F. Masoero, and L. Calamari. 1999. Relationship between body condition score, metabolic profile, milk yield and milk composition in goats browsing a Mediterranean shrubland. Livest. Prod. Sci. $61: 267-273$.

Caroprese, M., M. Albenzio, A. Marzano, L. Schena, G. Annicchiarico, and A. Sevi. 2010. Relationship between cortisol response to stress and behavior, immune profile, and production performance of dairy ewes. J. Dairy Sci. 93:2395-2403.

Chacón, G., S. Garcia-Belenguer, J. C. Illera del Portal, and J. Palacio. 2004. Validation of an EIA technique for the determination of cortisol. Span. J. Agric. Res. 2:45-51.

Díaz, J. R., M. Alejandro, G. Romero, F. Moya, and C. Peris. 2013. Variation in milk cortisol during lactation in Murciano-Granadina goats. J. Dairy Sci. 96:897-905.

Díaz, J. R., G. Romero, R. Muelas, E. Sendra, J. C. F. Pantoja, and C. Paredes. 2011. Analysis of the influence of variation factors on electrical conductivity of milk in Murciano-Granadina goats. J. Dairy Sci. 94:3885-3894.

Fox, L., W. R. Butler, R. W. Everett, and R. P. Natze. 1981. Effect of adrenocorticotropin on milk and plasma cortisol concentrations. J. Dairy Sci. 64:1794-1803.

Gilbert, G. R., G. L. Hargrove, and M. Kroger. 1973. Diurnal variations in milk yield, fat yield, milk fat percentage, and milk protein percentage of Holstein-Friesian cows. J. Dairy Sci. 56:409-410.

Gonzalo, C., J. A. Carriedo, J. D. Gómez, L. D. Gómez, and F. San Primitivo. 1994. Diurnal variation in the somatic cell count of ewe milk. J. Dairy Sci. 77:1856-1859.

Greenwood, P. L., and D. A. Shutt. 1992. Salivary and plasma cortisol as an index of stress in goats. Aust. Vet. J. 69:161-163.

Hagen, K., D. Lexer, R. Palme, J. Troxler, and S. Waiblinger. 2004. Milking of Brown Swiss and Austrian Simmental cows in a herringbone parlour or an automatic milking unit. Appl. Anim. Behav. Sci. 88:209-225.

Harmon, R. J., R. J. Eberhart, D. E. Jasper, B. E. Langlois, and R. A. Wilson. 1990. Microbiological procedures for the diagnosis of bovine udder infection. National Mastitis Council, Arlington, VA.

Higashiyama, Y., M. Nashiki, H. Narita, and M. Kawasaki. 2007. A brief report on effects of transfer from outdoor grazing to indoor tethering and back on urinary cortisol and behaviour in dairy cattle. Appl. Anim. Behav. Sci. 102:119-123.

Hopster, H., R. M. Bruckmaier, J. T. N. Van der Werf, S. M. Korte, J. Macuhova, G. Korte-Bouws, and C. G. Van Reenen. 2002. Stress responses during milking; comparing conventional and automatic milking in primiparous dairy cows. J. Dairy Sci. 85:3206-3216. 
Lefcourt, A. M., J. Bitman, S. Kahl, and D. L. Wood. 1993. Circadian and ultradian rhythms of peripheral cortisol concentrations in lactating dairy cows. J. Dairy Sci. 76:2607-2612.

Mehdid, M. E. 2009. Efecto del celo y del estrés sobre el recuento de células somáticas en la leche de cabra. [Effect of estrus and stress on somatic cell count in goat milk]. Doctoral Thesis. Universidad Politecnica, Valencia, Spain. http://riunet.upv.es/bitstream/ handle/10251/6846/tesisUPV3201.pdf.

Mudron, P., J. Rehage, H. P. Sallmann, M. Höltershinken, and H. Scholz. 2005. Stress response in dairy cows related to blood glucose. Acta Vet. (Brno) 74:37-42.

Munro, C. J., and B. L. Lasley. 1988. Non-radiometric methods for immunoassay of steroid hormones. Prog. Clin. Biol. Res. 285:289 329

Ndibualonji, B. B., D. Dehareng, C. Vaneenaeme, and J. M. Godeau. 1995. Response of milk yield, plasma-cortisol, amino-acids, urea and glucose to a single low-dose administration of adrenocorticotropic hormone in lactating cows. Vet. Res. 26:32-42.

Negrão, J. A., M. A. Porcionato, A. M. de Passille, and J. Rushen. 2004. Cortisol in saliva and plasma of cattle after ACTH administration and milking. J. Dairy Sci. 87:1713-1718.

Palme, R., and E. Mostl. 1997. Measurement of cortisol metabolites in feces of sheep as a parameter of cortisol concentration in blood. Int. J. Mammal. Biol. 62:192-197.

Smith, V. G., E. M. Convey, and L. A. Edgerton. 1972. Bovine serum corticoid response to milking and exteroceptive stimuli. J. Dairy Sci. 55:1170-1173.
Smith, J. W., and W. D. Schultze. 1967. Variation in cell content of milk associated with time of sample collection. I. Diurnal variation. J. Dairy Sci. 50:1083-1087.

Termeulen, S. B., W. R. Butler, and R. P. Natzke. 1981. Rapidity of cortisol transfer between blood and milk following adrenocorticotropin injection. J. Dairy Sci. 64:2197-2200.

Toerien, C. A., R. Puchala, J. P. Mc Cann, T. Sahlu, and A. L. Goetsch. 1999. Adrenocortical response to ACTH in Angora and Spanish goat wethers. J. Anim. Sci. 77:1558-1564.

Van Reenen, C. G., J. T. N. Van der Werf, R. M. Bruckmaier, H. Hopster, B. Engel, J. P. T. M. Noordhuizen, and H. J. Blokhuis. 2002. Individual differences in behavioral and physiological responsiveness of primiparous dairy cows to machine milking. J. Dairy Sci $85: 2551-2561$.

Verkerk, G. A., A. M. Phipps, J. F. Carragher, L. R. Matthews, and K. Stelwagen. 1998. Characterization of milk cortisol concentrations as a measure of short-term stress responses in lactating dairy cow. Anim. Welf. 7:77-86.

Wagner, W. C., and S. L. Oxenreider. 1972. Adrenal function in the cow, diurnal changes and the effects of lactation and neurohypophyseal hormones. J. Anim. Sci. 34:630-635.

Whittlestone, W. G., R. Kilgour, H. de Langen, and G. Duirs. 1970. Behavioral stress and cell count of bovine milk. J. Milk Food Technol. 33:217-220. 